\title{
The acute effect of meals rich in re-used deep-fried oil on endothelial function
}

\author{
S. E. E. Berry ${ }^{1}$, E. Abbas $^{1}$, S. Fissler ${ }^{1}$, P. J. Chowienczyk ${ }^{2}$, T. A. B. Sanders ${ }^{1}$ and W. L. Hall ${ }^{1}$ \\ ${ }^{1}$ Nutritional Sciences Research Division, King's College London, 150 Stamford Street, London SE1 9NN, UK \\ and ${ }^{2}$ Cardiovascular Division, King's College London School of Medicine, St Thomas' Hospital, London SE1 7EH, UK
}

The consumption of high-fat foods fried in oil that has undergone repeat cycles of heating contributes a notable proportion to UK dietary fat intake ${ }^{(1,2)}$. High-fat meals have been found to impair endothelial function ${ }^{(3)}$, which is believed to be mediated via an oxidative stress mechanism $^{(4)}$; however, few studies have examined the postprandial effects of thermally-oxidised fats commonly used in the UK for repeated deep-frying ${ }^{(5)}$.

The present study was designed to investigate the postprandial effects of commercially-used fresh oil and re-used deep-fried oil (palm oleic-mid-oleic sunflower oil blend) on endothelium-dependent vasodilation, which was determined using brachial artery flow-mediated dilatation (FMD). Nineteen healthy male subjects (aged 18-40 years) were fed test meals containing $50 \mathrm{~g}$ fat in a randomised cross-over design. The test fats were fresh or re-used deep-fried oil $\left(10 \mathrm{~d}\right.$ frying at $180^{\circ} \mathrm{C}$ with five batches of potato chips per d) containing $7.2 \%$ and $23.8 \%(\mathrm{v} / \mathrm{v})$ polar compounds respectively and $1.0 \mathrm{meq} / \mathrm{kg}$ and $4.4 \mathrm{meq} / \mathrm{kg}$ peroxides respectively. Plasma TAG and NEFA concentrations and FMD were determined fasting and $3 \mathrm{~h}$ postprandially.

Following the fresh oil the postprandial increase in plasma TAG was significantly higher compared with that following the fried oil. There was a significant meal effect $(P=0.04)$ for FMD but post-hoc analysis revealed no significant differences between meals at $3 \mathrm{~h}$ and no significant differences in the $3 \mathrm{~h}$ postprandial change in FMD.

\begin{tabular}{|c|c|c|c|c|c|c|c|c|}
\hline & \multicolumn{4}{|c|}{ Fresh oil $(n$ 19) } & \multicolumn{4}{|c|}{ Fried oil $(n$ 19) } \\
\hline & \multicolumn{2}{|c|}{$0 \mathrm{~h}$} & \multicolumn{2}{|c|}{ Change at $3 \mathrm{~h}$} & \multicolumn{2}{|c|}{$0 \mathrm{~h}$} & \multicolumn{2}{|c|}{ Change at $3 \mathrm{~h}$} \\
\hline & Mean & $95 \% \mathrm{CI}$ & Mean & $95 \% \mathrm{CI}$ & Mean & $95 \% \mathrm{CI}$ & Mean & $95 \% \mathrm{CI}$ \\
\hline Plasma TAG**十† & 1.0 & $0.8,1.2$ & 1.0 & $0.7,1.2$ & 1.1 & $0.9,1.4$ & $0.5 \S$ & $0.2,0.7$ \\
\hline NEFA** & 0.4 & $0.3,0.5$ & -0.2 & $-0.3,-0.1$ & 0.4 & $0.4,0.5$ & -0.1 & $-0.2,-0.0$ \\
\hline $\begin{array}{l}\text { Baseline brachial artery } \\
\text { diameter }(\mathrm{mm})\end{array}$ & 3.6 & $3.4,3.9$ & 0.0 & $0.0,0.01$ & 3.6 & $3.4,3.9$ & 0.0 & $-0.1,0.0$ \\
\hline $\begin{array}{l}\text { Post-hyperaemia brachial artery } \\
\text { diameter }(\mathrm{mm})\end{array}$ & 3.9 & $3.6,4.1$ & 0.0 & $-0.1,0.1$ & 3.9 & $3.7,4.1$ & 0.0 & $-0.1,0.0$ \\
\hline $\operatorname{FMD}(\%) \neq$ & 7.1 & $5.2,9.0$ & -0.3 & $-1.3,0.6$ & 8.3 & $6.5,10.1$ & -0.6 & $-2.0,0.8$ \\
\hline
\end{tabular}

Time effect (ANOVA): **P<0.01. Meal $\times$ time interaction (ANOVA): $\dagger \dagger P<0.01$. Meal effect (ANOVA): $\ddagger P<0.05$. Mean value was significantly different from that for fresh oil (paired $t$ test on mean change): $\S P<0.05$.

The lower postprandial TAG response following the fried oil is likely to be a consequence of degradation of TAG to other lipid fractions. Existing evidence demonstrates an association between postprandial lipaemia and impaired FMD ${ }^{(3)}$, but in the current study the greater TAG response following the fresh oil did not result in a significant impairment in FMD compared with the fried oil. This finding suggests that other mechanisms, such as increased oxidative stress, may have also influenced postprandial endothelial function. This outcome merits further research into the interaction between deep-fried oils, oxidative stress and endothelial function.

Special thanks to K McNeill and B Jiang, Cardiovascular Division, King's College London, St Thomas' Hospital, London, UK and Jo Bruce, ADM-PURA, Erith, UK.

1. Henderson L, Gregory J, Irving K et al. (2008) National Diet and Nutrition Survey. London: The Stationery Office.

2. Nelson M, Erens B, Bates B et al. (2007) Low Income Diet and Nutrition Survey. London: The Stationery Office.

3. Vogel RA, Corretti MC \& Plotnick GD (1997) Am J Cardiol 79, 350-354.

4. Bae JH, Bassenge E, Kim KB et al. (2001) Atherosclerosis 155, 517-523.

5. Hall WL (2009) Nutr Res Rev 22, 18-38. 